\title{
Folie induite: relato de um caso à margem das classificações atuais
}

\author{
Folie induite: report of a case outside of the actual classifications
}

Fernando Toledo da Cunha', Rodolfo Braga Ladeira', João Vinícius Salgado 2,3, Rodrigo Nicolato 2,4

\section{RESUMO}

Na classificação de Gralnick, de 1942, a folie à deux é dividida em quatro subtipos básicos: folie imposée, folie communiquée, folie simultannée e folie induite. O último termo se refere à adição de novas idéias delirantes por paciente previamente psicótico sob influência de outro paciente. Relatamos um caso de folie induite ocorrido entre mãe e filho primariamente psicóticos (transtorno delirante e esquizofrenia, respectivamente), que passaram a compartilhar delírios de natureza persecutória e sexual. Casos de folie à deux geralmente correspondem ao transtorno psicótico induzido (DSM-IV-TR) ou transtorno delirante induzido (CID-10). No entanto, o paciente deste relato não pode receber tais diagnósticos, já que nos critérios validados atualmente percebe-se a exigência de que o parceiro induzido não possua um transtorno psicótico anterior ao início do compartilhamento do delírio. Consideramos que o presente relato exemplifica a insuficiência das modernas classificações nesta área. Casos de folie induite podem necessitar de manejo distinto dos demais casos de psicose compartilhada ou não compartilhada. Sugerimos que os critérios diagnósticos correntes poderiam ser revisados para incluir condições psiquiátricas como essa.

\begin{abstract}
In the Gralnick classification of 1942 the term folie à deux is classically divided into four basic subtypes: folie imposée, folie communiquée, folie simultannée and folie induite. This last one refers to the addiction of new delusions in a previous psychotic patient, under the influence of another patient. We report a case of folie induite that occurred between mother and son, both diagnosed previously with psychotic disorders (delusional disorder and schizophrenia, respectively), who started to share persecutory and sexual delusions. Cases of folie à deux generally correspond to the induced psychotic disorder in the DSM-IV-TR or the induced delusional disorder in the ICD-10. However, our patient do not meet neither diagnosis, since, in both, it is necessary that the induced delusional patient do not have any previous psychotic disorder. We think that our report underscores the insufficiency of the modern classifications in this area. Cases of folie induite may require a management different from those used in other cases of shared or non-shared psychosis. We suggest that modern criteria should be revised to include cases such as the present one.
\end{abstract}

1 Instituto Raul Soares (IRS) - Fundação Hospitalar do Estado de Minas Gerais (FHEMIG), Belo Horizonte, MG.

2 Psiquiatria do HE-IRS-FHEMIG

3 Universidade Fundação Mineira de Educação e Cultura (FUMEC), Belo Horizonte, MG.

Recebido em

28/2/2008

Aprovado em

4 União Educacional do Vale do Aço (Univaço), I patinga, MG, Universidade José do Rosário Vellano (UNIFENAS), Belo Horizonte, MG e Instituto de Previdência dos Servidores de Minas Gerais. 


\section{INTRODUÇÃO}

Em 1877, Ernest Charles Lasègue e Jules Falret descreveram uma síndrome caracterizada pelo compartilhamento de sintomas psicóticos entre dois ou mais indivíduos e chamaram-na folie à deux (FaD). Embora referências anteriores sejam encontradas nos estudos de Ideler, em 1838, Baillager, em 1860 e De Saulle, em 1870', a criação do termo que se tornou clássico em psiquiatria, bem como sua introdução como entidade clínica, resultaram do histórico trabalho de Lasègue e Falret. Segundo os critérios originalmente delineados², a FaD era síndrome prevalente, principalmente, entre mulheres que viviam relativamente confinadas, assinalada pelo surgimento de: 1) sintomas psicóticos coincidentes em membros de uma família que vivesse reunida; 2) sintomas psicóticos em duas pessoas associadas intimamente; 3) transmissão de sintomas psicóticos de uma pessoa doente para um ou vários indivíduos saudáveis que passavam a aceitar o delírio induzido.

Em 1942, Gralnick reuniu descrições de diversos autores, ampliou e subdividiu o conceito de FaD, em quatro tipos básicos quanto às formas de apresentação ${ }^{1,3}$.

\section{Folie imposée}

A ideação delirante de um psicótico é transferida para alguém mentalmente saudável. A ideação "imposta" tende a desaparecer caso este último seja separado do indivíduo primariamente psicótico (descrito por Lasègue e Falret, em 1877).

\section{Folie communiquée}

O contágio das idéias delirantes ocorre depois de longo período de resistência. Uma vez efetivado, a ideação é mantida mesmo após a separação (descrito por Marandon de Montyel, em 1881).

\section{Folie simultannée}

Há o aparecimento simultâneo de psicose idêntica em duas pessoas morbidamente predispostas. A perturbação surge, em geral, depois de fatores desencadeantes, usualmente de natureza depressiva (descrito por Regis, em 1880).

\section{Folie induite}

Refere-se à adição de novas idéias delirantes, por paciente previamente psicótico, sob a influência de outro paciente (descrito por Lehmann, em 1885).

Em todos os subtipos é clássica a descrição da relação de dominância e submissão entre os envolvidos'. Fatores como maior idade, inteligência, educação, impulsividade, agressividade e poder de sugestão indicariam o "caso primário", no qual os sintomas surgiram primeiramente. Perturbações da personalidade com traços de dependência, sugestiona- bilidade, inteligência subnormal, prejuízo sensorial e baixa auto-estima acarretariam a submissão no chamado "caso secundário".

Este relato tem como objetivo descrever a ocorrência de um raro caso compatível com a descrição de folie induite e discutir sua classificação diante das atuais descrições clínicas e diretrizes diagnósticas.

\section{RELATO DO CASO}

H, dona-de-casa de 66 anos, viúva, ensino fundamental incompleto e seu filho RC, 38 anos, solteiro, ensino fundamental completo, aposentado há 10 anos, foram internados no Instituto Raul Soares (IRS) depois de episódio de agitação psicomotora e heteroagressividade direcionada aos vizinhos.

Durante a internação, $\mathrm{H}$ e RC apresentaram delírios sistematizados de conteúdo persecutório e sexual. Afirmavam que os vizinhos tentavam envenená-los, jogando veneno na caixa d'água, e que todo pai deveria estuprar seu filho quando a criança estivesse com três anos de idade. Caso isso não acontecesse, ela cresceria doente, "destruída prá vida toda", como no caso de RC, que não fora devidamente "orientado" pelo pai. Seus discursos eram praticamente idênticos. RC descrevia também alucinações cenestésicas. Queixavam-se da separação, pois nunca haviam ficado tanto tempo distantes um do outro.

RC evoluiu com atenuação importante dos sintomas iniciais e passou a defender com menos "paixão" suas idéias paranóides. H, que possuía quadro essencialmente delirante, evoluiu com discreta melhora clínica. $\mathrm{RC}$ e $\mathrm{H}$ receberam alta depois de quatro semanas de internação com hipóteses diagnósticas, pela CID-10, de esquizofrenia paranóide e transtorno delirante, respectivamente.

Familiares relataram que $\mathrm{H}$ começou a manifestar alterações comportamentais cerca de 25 anos antes, aos 40 anos de idade. Tornou-se desconfiada, "supersticiosa", afastada do convívio social e restrita ao seu núcleo familiar. Os sintomas de RC, por outro lado, iniciaram-se em 1987, aos 18 anos de idade. Em sua história, enumeram-se atividade delirante sistematizada persecutória, auto-referente, cenestopática e bizarra, diferente da apresentada atualmente, além de postura alucinatória e incongruência afetiva.

\section{DISCUSSÃO}

As alterações de $\mathrm{H}$ e RC começaram há cerca de 20 e 25 anos, aproximadamente. As primeiras informações quanto ao início do compartilhamento de idéias delirantes persecutórias entre H e RC datam de 1996. Embora seja possível que já dividissem tais idéias há algum tempo, a história 
pregressa de RC indica a ausência dos delírios atualmente compartilhados no início de seu adoecimento. Isso sugere a ocorrência de um delírio compartilhado por dois indivíduos primariamente psicóticos.

Na classificação de Gralnick, o presente caso seria classificado como FaD, subtipo folie induite, em que um doente adiciona aos seus delírios iniciais novas idéias delirantes de um ou vários doentes. Nesse ponto, vale a pena tentar identificar os casos primário e secundário. Dessa forma, considera-se $\mathrm{H}$ o caso primário, pois preenche um maior número de critérios que identificam o parceiro dominante, incluindo maior poder de sugestão, ao passo que o oposto se aplica a RC, ou seja, seus traços de dependência, menor inteligência e sugestionabilidade o encaixam melhor como caso secundário.

O caso de He RC também preenche as diretrizes propostas por Dewhurst e Todd, em 1956, para estabelecimento de critérios mais precisos para o diagnóstico de FaD, evitando o uso indiscriminado do termo para designar qualquer perturbação mental envolvendo duas ou mais pessoas com um maior grau de associação: a) associação íntima e prolongada entre os envolvidos; b) tema delirante similar; c) os parceiros aceitam, compartilham e apóiam cada um o delírio do outro.

Atualmente, casos em que há transferência de sintomas psicóticos entre duas pessoas recebem a denominação de transtorno delirante induzido, pela CID-10, ou transtorno psicótico induzido, segundo o DSM-IV-TR. Casos como o de RC, entretanto, não podem ser classificados dessa forma. Nos critérios diagnósticos atuais dessas nosologias, há a exigência de que o caso secundário não tenha um transtorno psicótico anterior ao início do delírio induzido e compartilhado ${ }^{4-6}$. Assim, RC recebe diagnóstico de esquizofrenia paranóide, enquanto $\mathrm{H}$, de transtorno delirante.

Entretanto, na maior e mais atual revisão de relatos de caso sobre este tema, Arnone et al.7, apontam discrepâncias entre os 42 casos descritos de 1993 a 2005 e os critérios classificatórios atuais. Essa revisão indica alta taxa de comorbidade psiquiátrica nos casos secundários (28,6\% a 89\%), inclusive esquizofrenia (14,3\%). Os autores argumentam que, em alguns casos, o convívio entre os casos primário e secundário poderia funcionar como um gatilho para eclosão ou agravamento de sintomas, mas sem serem imprescindíveis para os mesmos.

A verificação de que o fenômeno da transferência de sintomas psicóticos entre duas pessoas pode ocorrer em situações distintas das previstas nas classificações atuais levanta importantes questões para o manejo dos pacientes. Por exemplo, em casos de FaD clássica, o tratamento principal para o caso secundário seria sua separação do caso primário. Nos casos secundários que apresentam comorbidade, inclusive esquizofrenia, a importância relativa dessa separação não é clara?. Essa falta de informação pode estar ligada justamente à falta de reconhecimento dos casos.

\section{CONCLUSÃO}

Sugerimos que os critérios diagnósticos correntes, à luz dos relatos e das evidências mais recentes, revelam-se insuficientes e deveriam ser revisados para incluir gama mais ampla de condições psiquiátricas e contemplar, por exemplo, a possibilidade de alteração psiquiátrica primária, inclusive da ordem das psicoses, no caso secundário.

\section{REFERÊNCIAS}

1. Teixeira PJR, Araújo GC, Rocha FL. Folie à deux - revisão crítica da literatura. J Bras Psiq. 1992:41(2):61-5

2. Cordeiro Jr. Q, Corbett CEP. Delírio de infestação parasitária e folie à deux: relato de caso. Arq neuro-psiquiatr. 2003;61(3B):872-5.

3. Lima CAM. Um caso de folie à deux: revisão da literatura. J Bras Psiq. 1987;36(6):317-20.

4. Classificação de transtornos mentais e do comportamento da CID-10. Porto Alegre: Artes Médicas, 1993.

5. DSM-IV-TR. Manual diagnóstico e estatístico dos transtornos mentais. 4. ed. rev., Porto Alegre: Artmed; 2002.

6. Patel AS, Arnone D, Ryan W. Folie à deux in bipolar affective disorder: a case report. Bipolar disord. 2004:6:162-5

7. Arnone D, Patel A, Tan GMY. The nosological significance of folie a deux: a review of the literature. Annals general psychiatry, 2006:5:1. 